\title{
7 \\ AM/FM/GIS Applications for Stormwater Systems
}

Uzair M. Shamsi and Bruce A. Fletcher

This chapter presents an overview of the automated mapping/facilities management/geographic information system (AM/FM/GIS) capabilities and applications for the management of stormwater systems. Created by integrating GIS and AM/FM systems, AM/FM/GIS systems represent a new trend in the stormwater utility industry. A review of popular AM/FM/GIS software is presented. AM/ FM/GIS database development procedures and examples are given. A list of typical stormwater database attributes is provided. Six case studies are presented to illustrate the application of AM/FM/GIS technology for stormwater systems.

\subsection{Introduction}

Infrastructure is a Latin word meaning "the structure underneath." The water, stormwater, and wastewater infrastructure is aging throughout the world. The American Society of Civil Engineers (ASCE) projects $\$ 1.3$ trillion in infrastructure needs in the USA over the next five years alone, of which approximately one third is needed for water and wastewater improvements. Unfortunately, adequate federal funds are not available. This problem can be partially blamed on the "out of sight - out of mind" mentality of the decision makers. The lack of funding for badly needed infrastructure improvements is a concern. This is evident in recently conducted public opinion polls. According to a recent survey, $31 \%$ of

Shamsi, U.M. and B.A. Fletcher. 2000. "AM/FM/GIS Applications for Stormwater Systems." Journal of Water Management Modeling R206-07. doi: 10.14796/JWMM.R206-07.

(C) CHI 2000 www.chijournal.org ISSN: 2292-6062 (Formerly in Applied Modeling of Urban Water Systems. ISBN: 0-9683681-3-1) 
Americans would rather not swim in the nearest river. A 1998 ASCE poll showed that more than $75 \%$ of the United States voters were concerned about the quality of roads, drinking water and school buildings. In Boston, more voters were concerned about roads, bridges and drinking water than Social Security and taxes. In New York City, school buildings and drinking water concerns out scored drug abuse worries (ASCE, 1998). Many indicated that they will vote for a candidate whose election campaign addresses waste disposal (78\%), drinking water $(73 \%)$, and roads and bridges $(62 \%)$. These surveys indicate that waterrelated infrastructure is particularly important because it is so closely related to public health and safety.

Stormwater systems are an important part of the water related infrastructure. Over the past two decades, local, regional, and national-scale research programs have shown that pollutants discharged from municipal separate storm systems are among the principal causes of water quality problems in most urban areas (Murillo et al., 1996). Improper stormwater systems can impact the operation of both the drinking water and wastewater systems. Drinking water can be impaired due to pollution of surface water supply sources from polluted stormwater outfall discharges. Wastewater collection and treatment can be impacted by unwanted inflow of stormwater into the sanitary sewer systems.

One of the biggest challenges of rapid urban growth is managing information about maintenance of existing infrastructure and construction of new infrastructure. Many utilities tackle infrastructure problems on a react-to-crisis basis which may not be the best strategy. Making informed infrastructure improvement decisions requires a large amount of diverse information on a continuing basis. If information is the key to solving infrastructure problems, the first step of any infrastructure improvement project should be the development of an information system (see also Chapter 2 in this monograph). An information system is a framework by which to ask questions and obtain answers from a data resource. More than $80 \%$ of all the information used by utilities is geographically referenced, that is, a key element of the information is its location relative to geographic features, other objects, established boundaries, etc. A geographic information system (GIS) is a special type of information system in which the database consists of observations on spatially distributed features and procedures to collect, store, retrieve, analyze, and display such geographic data. GIS links map features with database attributes. The integration of digital mapping and database capabilities is what sets GIS apart from other information systems. In the past decade, powerful personal computers and sophisticated software have combined to bring GIS capability to any desktop.

Computer aided design and drafting (CADD) is used for designing and drafting new structures. Computer aided mapping (CAM) is CADD technology applied to produce digital maps. CAM can be considered as a computerized alternative to traditional manual cartographic map making. Automated 
mapping/facilities management (AM/FM) is CADD technology applied to manage utility system data. Compared to GIS, AM/FM places less emphasis on graphics detail or precision and more emphasis on data storage, analysis, and reporting. Unlike GIS, AM/FM systems do not have spatial relations (topology). In $\mathrm{AM} / \mathrm{FM}$, relationships among utility system components are defined as networks. Simply stated, GIS emphasizes location and topology (spatial relationships) and AM/FM emphasizes database and connectivity. Table 7.1 presents a comparison of CAM, AM/FM, and GIS systems.

Table 7.1 Comparison of CAM, AM/FM, and GIS.

\begin{tabular}{lccc}
\multicolumn{1}{c}{ Feature } & CAM & AM/FM & GIS \\
\hline Layers & Y & Y & Y \\
Topology & N & N & Y \\
Network analysis & N & Y & Y \\
Lines & Y & Y & Y \\
Nodes & N & Y & Y \\
Polygons (areas) & N & N & Y \\
Attributes & N & Y & Y \\
Actual locations & Y/N & Y & Y \\
Map intelligence & N & N & Y \\
\hline
\end{tabular}

\title{
7.2 AM/FM/GIS Applications
}

\begin{abstract}
$\mathrm{AM} / \mathrm{FM}$ can also be defined as a digital infrastructure management database. A digital system is less expensive to manage and maintain and more efficient than any existing manual approach and this translates into cost savings. Information is readily available at your fingertips. AM/FM provides access to the latest inventory, maintenance, inspection, and historical information, with the capability to run complex engineering modeling scenarios. AM/FM allows the integration and automation of maintenance management. AM/FM can be used to improve work order management, capture maintenance data and cost, allocate cost, allow focusing of maintenance, and provide better integrated inventory control. Thus it can be said that the main objective of an AM/FM system is automation of maintenance and related activities.

It is obvious from the above discussion that GIS and AM/FM are different, and both have specific advantages and applications. A GIS can help locate the worst pipe. An AM/FM can help prioritize work required to bring the worst pipe up to a minimum operating standard. For many years, people have used both systems separately. Developing and maintaining two different systems is
\end{abstract}


expensive and inefficient. Thanks to the latest advances in computer hardware and software, integrated AM/FM and GIS systems called "AM/FM/GIS" systems are now available. As shown in the flow chart in Figure 7.1, these integrated systems have combined the best features of both systems. In the last five years, computers have become so powerful that AM/FM/GIS software will now run on off-the-shelf personal computers. Once the province of researchers and academicians, AM/FM/GIS are ready to infiltrate almost all areas of water, wastewater, and stormwater system management. For managers involved in planning, design, construction, and operation of stormwater systems the advent of AM/FM/GIS is timely. Representation and analysis of stormwater systems by $\mathrm{AM} / \mathrm{FM} / \mathrm{GIS}$ facilitates their management. By using geographic information from mapping, modeling, facilities management, and work order management, a stormwater system manager can develop a detailed capital improvement program or operations and maintenance plan. Linkage of GIS to computer models is particularly useful for storm sewer modeling applications. Thus, it seems likely that $\mathrm{AM} / \mathrm{FM} / \mathrm{GIS}$ use will continue to proliferate in the areas of stormwater management. The AM/FM/GIS GIS applications that are of particular importance to stormwater system managers are: Mapping, Monitoring, Modeling, and $M$ aintenance. These four $M s$ define the four most important activities which can be conducted efficiently using AM/FM/GIS systems.

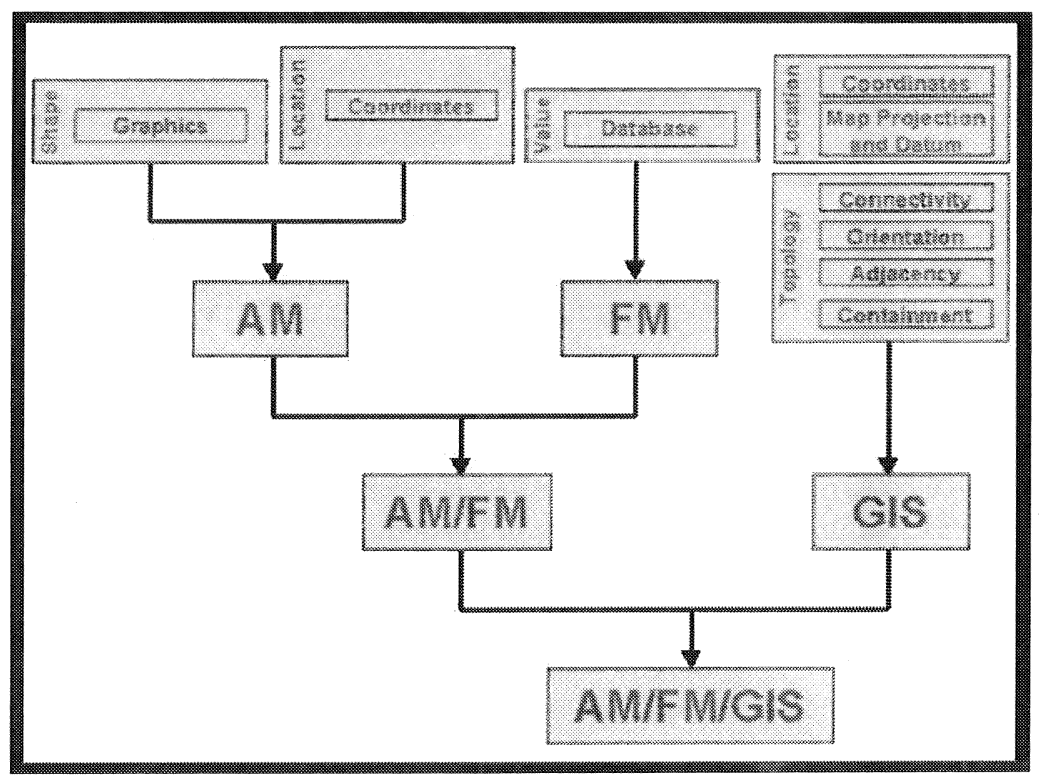

Figure 7.1 AM/FM/GIS software structure. 
An AM/FM/GIS system provides a basis for comparing the geographic patterns of probable pollutant sources, observed pollution problems, actual management efforts (e.g. structural and non-structural best management practices (BMPs)), and spending patterns for pollution controls. Regulatory agencies can use an AM/FM/GIS based stormwater management information system to (Murillo, 1996):

- track and report on current NPDES permit activities

- trace and record pollution problems in the field

- track polluters and violations, and

- predict water quality throughout the storm sewer system

\subsection{AM/FM/GIS Database Design}

A utility GIS database consists of graphic features and labels, with links or pointers (usually facility identification numbers, IDs) to related attribute or tabular data. The features are usually organized into a series of vector layers consisting of points, lines, or polygons that are registered to a geographic control framework and a set of base information called a base map. Table 7.2 shows typical stormwater system features and how they are mapped in GIS. The common reference base provides registration between geographic features which enables combinations of layers to be overlaid, viewed, analyzed, and plotted together (Cannistra, 1999).

Table 7.2 Stormwater system features.

\begin{tabular}{lll}
\hline \multicolumn{1}{c}{ Line } & \multicolumn{1}{c}{ Node } & \multicolumn{1}{c}{ Point } \\
\hline Pipe & Manhole & Cleanout \\
Channel & Pumping station & Vault \\
Culvert & Infiltration basin & Flow meter \\
Siphon & Retention basin & \\
Stream & Inlet & \\
Casing & Outfall & \\
& Cleanout & \\
& Pipe fittings & \\
\hline
\end{tabular}

Typical information required to manage a stormwater system includes:

- physical characteristics of the storm water system

- receiving waters outfall locations

- service area land use

- service area polluters

- service area pollutants

- concentrations and annual loads of the pollutants, and

- pollution control measures 
Database design involves two steps: (i) conceptual or logical design and (ii) physical design. Conceptual design defines graphic features, attributes, labels, data format, reports, feature placement rules and guidelines, and database output, etc. Physical design specifies system-specific database structure, data layers, feature symbology, file names, table names, attributes names, and key IDs, etc. Before a systemwide implementation, the initial database design and data conversion methodology should be evaluated for a small pilot area and fine-tuned if necessary.

An AM/FM/GIS system database has two components:

1. Assets Data: These are the necessary utility assets data that define the physical characteristics of the system. They are necessary for developing the GIS and are needed at the outset. Stormwater infrastructure inventory data are the core component for tracking maintenance operations. These data represent the "AM/GIS" component of an AM/FM/GIS system. Figure 7.2 shows an ArcView GIS implementation of a sewer system.

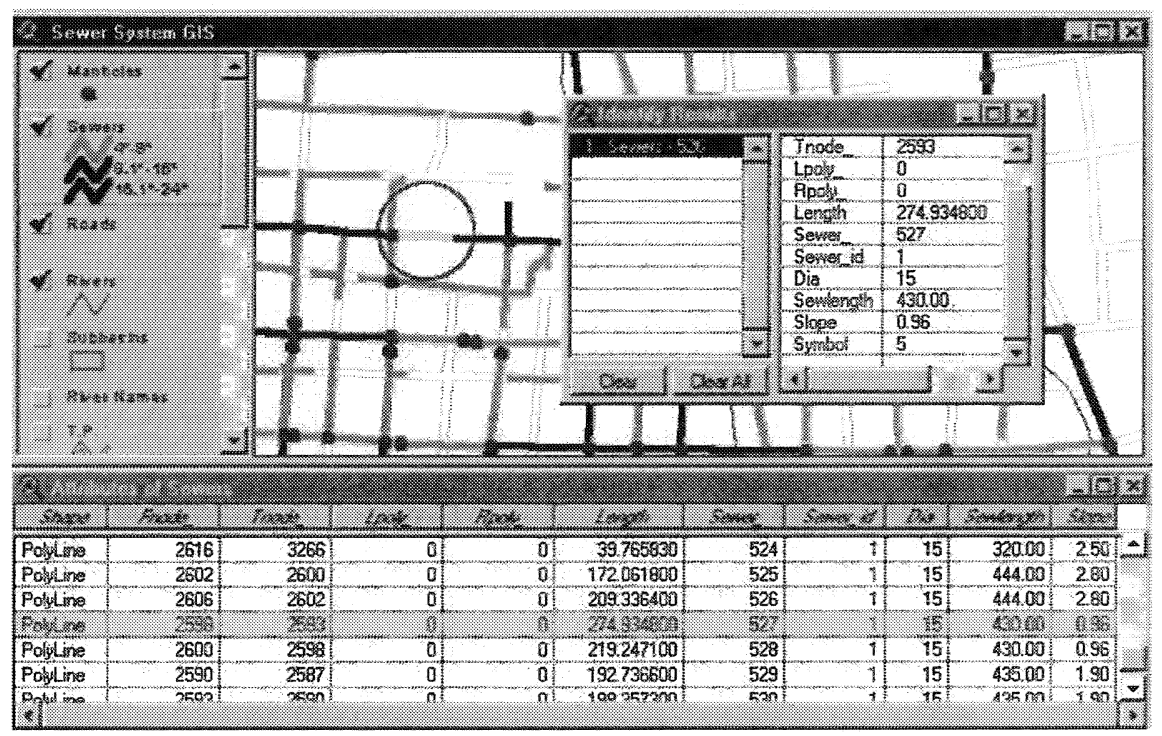

Figure 7.2 Sewer system GIS example.

2. Applications Data: These data are required for running FM applications, such as work order management, planning, and hydraulic modeling. They are needed at the time that applications are being developed. These data represent the "FM" component of an AM/ FM/GIS system. 
How data are categorized is often subjective. For example, some users may consider a digital orthophoto base map to be necessary to build accurate GIS layers of the physical system and enlist them under the assets category. Others may regard orthophotos an optional luxury item to enhance data visualization and include them in the applications category. Typical data items required under each data category are listed below. This list is general and should be modified by adding more system-specific items or deleting unnecessary items.

\section{Assets Data}

- Storm sewer

Street address

Upstream (from) ID

Downstream (to) ID

Shape

Diameter

Length

Upstream Invert elevation

Downstream Invert elevation

Slope

Depth

Friction factor

Pipe type

Force main / gravity sewer

Material

Joint length

Date installed

Groundwater level

- Manhole

Street address

Cover material

Cover type

Top elevation

Invert elevation

Depth

Shape

Size (diameter, etc.)

Ring
- Manhole continued

Wall

Frame

Steps

Bench

Channel

Meter

Drop manhole

Distance to hydrant

Air release manhole

Pipe(s) in and out

Invert elevation

Diameter

Direction

Type

Groundwater level

- Channel

- Ditch

- Swale

- Outfall

- Inlet

- Catchbasin

- Pumping station

- Tide gate

- Detention pond

- Retention pond

- BMP location

- Dam

- Culvert

\section{Applications Data}

- Base map:

Digital Orthophoto Basemap (DOB)

Aerial photos

USGS Digital Raster Graphics (DRG) or topographic map images

USGS Digital Line Graphs (DLG)

USGS Digital Orthophoto Quads (DOQ)

Satellite imagery

- USGS Digital Elevation Model (DEM)

- Streets (geocoded)

- Land use / land cover

- Industries 
- Soils

- Hydrography

- Geology

- Parcels

- Census blocks and block groups

- Watershed boundaries

- Subbasin / sewershed boundaries

- Building footprints

- Right of way

- Wetlands

- Flood plains

- Flow monitors

- Water quality samplers

- Rain gages

- Field inspections

- NPDES Compliance Data

Field data

Dry weather testing data

Wet weather testing data

Land use

- Identify potential sources of stormwater pollution and drainage defects TV inspections

Manhole inspections

Smoke testing

Dye testing

- Condition ratings to prioritize critical pipes:

Structural

Root

Hydraulic

- Preventive maintenance

Periodic cleaning

Flushing

Inspections

\subsection{AM/FM/GIS Software}

There are two types of AM/FM/GIS software:

1. AM focus: These software provide more mapping (AM) capabilities. ArcFM is an example of this type of software.

2. FM focus: These software provide more database (FM) capabilities. Pipeworks is an example of this type of software.

Table 7.3 provides a list of some popular AM/FM/GIS software. ArcFM and Pipeworks programs are described below. Note that IMS and CASS WORKS packages are sold as implementation projects rather than computer programs. 
Table 7.3 AM/FM/GIS software.

\begin{tabular}{llll}
\hline \multicolumn{1}{c}{ Software } & \multicolumn{1}{c}{ Vendor } & \multicolumn{1}{c}{ Main Features } & Other Software Needed \\
\hline ArcFM & $\begin{array}{l}\text { ESRI, } \\
\text { Redlanda, CA }\end{array}$ & $\begin{array}{l}\text { Objects based drawing and } \\
\text { editing of utility system maps } \\
\text { Software available for purchase }\end{array}$ & $\begin{array}{l}\text { ARC/INFO, SDE, } \\
\text { RDBMS }\end{array}$ \\
\hline Pipeworks & $\begin{array}{l}\text { Azteca Systems, } \\
\text { Sandy, UT }\end{array}$ & $\begin{array}{l}\text { An ArcView Extension for } \\
\text { computerized maintenance } \\
\text { management } \\
\text { Software available for purchase }\end{array}$ & $\begin{array}{l}\text { ArcView 3.x, ODBC } \\
\text { driver, SQL database }\end{array}$ \\
\hline $\begin{array}{l}\text { IMS Stormwater } \\
\text { Module }\end{array}$ & $\begin{array}{l}\text { Hansen, } \\
\text { Sacramento, CA }\end{array}$ & $\begin{array}{l}\text { Stormwater Module linked to } \\
\text { several GIS software }\end{array}$ & $\begin{array}{l}\text { IMS and a GIS software } \\
\text { (ArcView, ARC/INFO, }\end{array}$ \\
$\begin{array}{l}\text { CASS WORKS } \\
\text { Storm } \\
\text { Maintenance } \\
\text { Module }\end{array}$ & RJN Group, & Software delivered with projects & Storm Maintenance Module \\
linked to ArcView GIS & CASS WORKS, \\
& & & Geo/CAD, ArcView \\
\hline
\end{tabular}

\subsubsection{ArcFM}

ArcFM is an off-the-shelf AM/FM/GIS application for the utility industry. It is developed jointly by Environmental Systems Research Institute (ESRI) and Miner and Miner. It is designed for editing, maintenance, modeling, and data management of utility information. The software is written in Visual Basic 5.0 for Windows and runs on the NT platform only. As shown in Figure 7.3 ArcFM has two components: (i) ArcFM: The main program for creating and editing maps and (ii) ArcFM Viewer: The companion program for querying and viewing maps created in ArcFM. ArcFM is suitable for the production work by GIS technicians. ArcFM Viewer is a simple program intended for managers to review and display finished maps. The relationship between ArcFM and ArcFM viewer is similar to the relationship between ARC/INFO and ArcView programs.

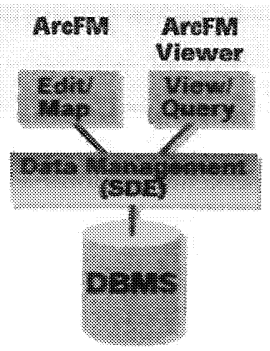

Figure 7.3 ArcFM Software Structure. 
In ArcFM features are modeled as objects with drag-and-drop capability. For example, to draw a catch basin, simply select the catch basin icon from the objects library and drag-and-drop it to its correct location. Thus, the GIS tools deal with features that are not simply points and lines, but valves, pipes, manholes, inlets, drainage basins, and more. ArcFM has a RuleBase Engine (RBE) which determines how features are drawn (symbology, placement, rotation, etc.). The RBE can be individualized for different applications. For example, the stormwater RBE may define pipes, their associated features, and the methods that pertain to them. RBE can also validate user-entered data to ensure valid attribute values. With the help of these capabilities, ArcFM can perform routine editing functions, such as adding a new catch basin or service connection or splitting a pipe.

ArcFM provides sample data model and business rules templates for water, wastewater, and stormwater systems. These templates, called "modules", can be modified for project specific applications. ArcFM does not have maintenance management capability but it can be integrated with other work management or customer information systems. ArcFM is not a standalone program. It requires ESRI's ARC/INFO and Spatial Database Engine (SDE) software and a relational database management system (RDBMS), such as Oracle, or Microsoft Access.

\subsubsection{Pipeworks}

Pipeworks is an ArcView Extension developed by Azteca Systems. Figure 7.4 shows the Pipeworks screen and menu. It works with ESRI coverages and shapefiles and stores project data in any SQL database, such as, SQL Anywhere, Oracle, Sybase, etc. Other programs required to run Pipeworks are an ODBC (32bit) driver, ArcView 3.x, and an external SQL database. Pipeworks capabilities include inventory, query, data editing, maintenance histories, work order management, map output, reporting, work order scheduling, network tracing, and inspections and condition ratings. Network tracing is a valuable tool for sewer system networks. For example, it can identify all the storm sewer pipes contributing flow to a given stormwater outfall. Pipeworks can also be used for managing and recording a TV inspection program for sewers. Figure 7.5 shows a Pipeworks' work order management screen.

The Pipeworks extension provides additional capabilities to make ArcView a complete work management system. The attribute data managed by Pipeworks are referred to as extended attributes because these attributes are stored in the extended coverage database or RDBMS. Examples of extended attributes includes additional inventory data, work orders, work histories, inspections, customer complaints and so forth. Pipeworks requires that all inventoried features be created and maintained as coverage data types: line, node or point 


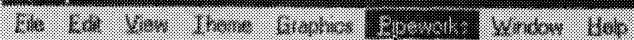

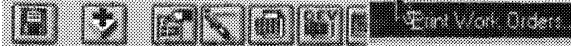

\section{[6IIIL [alo|}

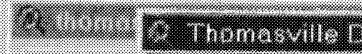

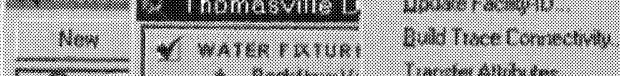

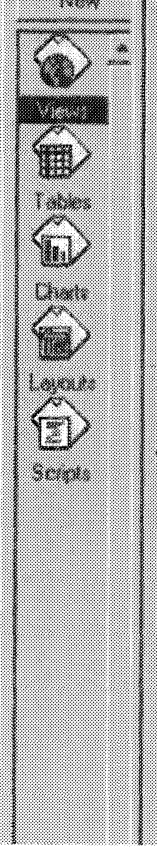

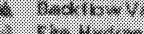

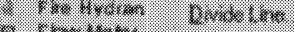

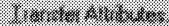

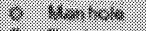

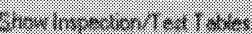

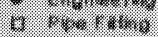

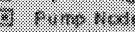

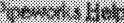

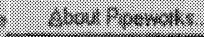

$4: 2: 3$

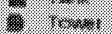

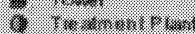

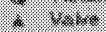

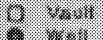

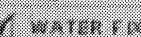

6. $0.2 \times 40$

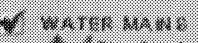

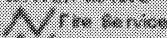

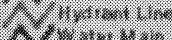

V.: : : : : : : : : : : : :

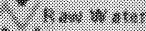

$10: 34: 4: 4: 4$

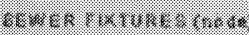

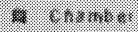

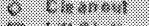

4.: $104: 4: 2: 3$

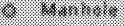

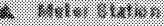

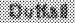

$.0 .1 .0 .10 .12: 3$

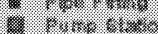

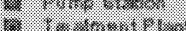

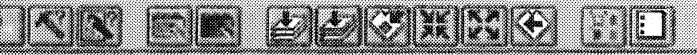

Figure 7.4 Pipeworks screen and menu. 


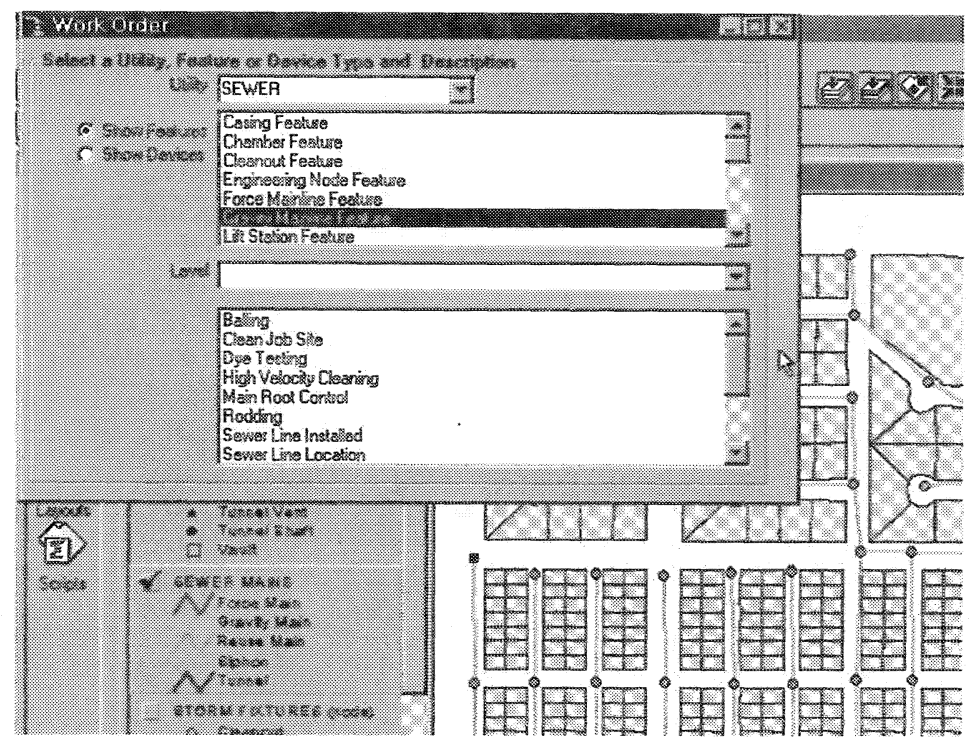

Figure 7.5 Pipeworks work order management screen.

feature. Pipeworks has a GIS-centric approach. Pipeworks does not "integrate" a work management system with GIS. It uses the GIS as a work management system. In other words, Pipeworks does not treat the GIS as subordinate to the work management system (Azteca, 1999).

\subsection{Case Studies}

Many utilities are turning to AM-FM-GIS systems to augment planning, design, operations, and maintenance activities (AWWA, 1999, Cannistra, 1999). Since $\mathrm{AM} / \mathrm{FM} / \mathrm{GIS}$ is a relatively new technology and implementation time is long (one to three years), most of the AM/FM/GIS projects are in the process of being implemented. Some sample projects are discussed below to illustrate the database design, hardware and software specifications, and maintenance management applications.

\subsubsection{LA's Stormwater Information Management System}

The City of Los Angeles' Stormwater Management Division has developed a GIS based Stormwater Management System (Murillo, 1996). The Division is organized into six sections: permit compliance, financial, engineering, public education, inspection, and monitoring. The mission of the Division is to implement 
and manage programs that ensure City compliance with Federal, State, and local flood control and stormwater pollution abatement laws and regulations, and to develop programs that ensure that storm drain discharges do not interfere with the beneficial uses of the City's receiving waters. The Stormwater Management Information System is designed to respond to both the stormwater pollution regulations and the City's flood control responsibilities.

Numerous workshops and meetings were conducted with each section to develop a conceptual database design and twelve targeted applications. Top management assigned priorities to each of the twelve applications and the following common data sets were identified:

1. street network,

2. parcels,

3. storm drain conveyance system,

4. land use,

5. hydrologic boundaries (watershed and sub-areas) and

6. jurisdictional boundaries.

The twelve prioritized applications were:

1. water quality model,

2. enhanced catch basin cleaning tracking,

3. catch basin stenciling tracking and reporting,

4. flood zone inquiry,

5. FEMA flood plain map revision tracking,

6. repetitive flood loss tracking,

7. school education program reporting,

8. BMP reporting by council district,

9. corporate sponsor tracking,

10. stormwater pollution abatement charge tracking,

11. industrial site investigation tracking and reporting,

12. pollution investigation trace.

The output from the water quality model is used to run the pollutant investigation trace utility which helps to target sources of pollutants within a given watershed. A user selects the outfall or other storm drain location and specifies the pollutant of concern. The application determines the extent of the drainage area to the selected location and then compares the selected pollutant to the Standard Industrial Classifications (SIC) of each of the parcels within the drainage area. A table developed by the Stormwater Management Divisions' inspection and monitoring sections is used to relate the parcel's SIC to possible pollutants. A map showing the parcels with matching pollutant source is created. A report is created which outlines each parcel's inspection history, enforcement actions, illegal dumping, or other information that may be helpful in determining the source of the pollution. Management is able to deal with real-time problems with a much more structured and targeted process. 


\subsubsection{Boston's Sewerage Analysis and Management System}

The Massachusetts Water Resources Authority (MWRA) provides wholesale water and wastewater services to 2.5 million people in 60 communities in the Greater Boston area. Perhaps best known for the $\$ 3.5$ billion upgrade of the Boston Harbor wastewater treatment plants, it also is responsible for the protection and maintenance of more than 800 square miles $\left(2067 \mathrm{~km}^{2}\right)$ of service area and watersheds, 780 miles $(1254 \mathrm{~km})$ of large-diameter pipeline, dozens of pumping stations, tunnels, and several treatment works. Over the last decade MWRA has developed a GIS to support its massive project operations and planning needs. The program grew from a tool to support general planning-level applications to a sewer system information management system called Sewerage Analysis and Management System (SAMS) that supports automated mapping, hydraulic modeling, site-specific analysis, maintenance, and facilities management (Estes-Smargiassi, 1999).

SAMS developed several data layers and applications to facilitate the automated mapping of sewerage facilities, hydraulic modeling of the wastewater collection system, and the planning and design of new collection facilities. SAMS enables users to view a street, click on a specific pipe and not only receive basic physical information, but also view the pipe's original design and record drawings. Thus, real-world accuracy still resides with the design drawings. SAMS uses ARC/INFO (including ARC GRID, ARC NETWORK, and ARC TIN modules), Oracle Forms 4.0, and SQL Writer. A current integration project will develop user-friendly interfaces to Oracle data through both Oracle Browser and ArcView. ArcView also will provide the front end for dBASE databases.

\subsubsection{Greensboro's GIS-Based Preventive Maintenance Program}

The City of Greensboro, North Carolina, is developing a unique GIS database as part of its comprehensive and proactive stormwater and watershed management program (Bryant et al., 1999). Their graphical and relational database includes information on drainage infrastructure and stormwater conveyance systems, drainage basin boundaries, floodplains, soils and hydrologic soil groups, existing land uses and zoning classifications, US-designated waters, storm sewer outfalls, structural BMPs, drainage and water quality complaints, topographic data including a digital terrain model, and water quality monitoring locations and data.

One of the goals of the Greensboro's program was to improve customer service by providing a better-designed and better-maintained stormwater system. An innovative database and GIS integration approach is used to optimize maintenance and tracking activities. Operators can use both a forms interface and a map to see the structures that require maintenance. Queries may be made on the map to complete the form, and database searches using the form can highlight 
features on the map. Graphical and textual hard copy may be generated. Work order items are highlighted on a hard-copy map, providing clear instructions for crews going into the field and facilitating rapid location of the site. The inventory database is updated automatically by the application as maintenance activities are performed.

\subsubsection{Surrey's Spatial Data Warehouse}

One of the fastest growing cities in Canada, the City of Surrey, British Columbia, operates and maintains a large network of drainage pipes, culverts, ditches, detention ponds, and other drainage structures. It covers an area of $365 \mathrm{sq} . \mathrm{km}$. and has a population of 325,000 . The City is developing a GIS based spatial data warehouse (Doherty and Speer, 1999) to achieve the following goals:

- provide attribute data in an external database (e.g. ORACLE)

- minimize cost of maintaining the data

- support for future expansion of fields in the database, and

- support for applications such as modeling and source control analysis.

The City has used ARC/INFO software to develop four databases:

1. Drainage conveyance elements: a network with attributes for lines and nodes. This database contains a single continuous network for all conduits that convey stormwater including service connections, mains, ditches, and creeks. An advantage of an integrated network structure is ease of data update. If a pipe is found to be off by $50 \mathrm{~cm}$, it can be moved in the drainage database, and all of the associated records for house connections will move with it. Thus a change made in one database is automatically reflected in other databases.

2. Detention ponds: polygons with attributes for polygons

3. Driveway culverts: points with no attributes

4. Dikes: polygons with no attributes

Since the ARC/INFO database is a proprietary format, its values are not accessible outside the GIS. The City, therefore adopted an "open" system design in which many different kinds of applications can access the database. Only a minimum number of attributes, representing links to external tables, are stored directly in GIS. The external tables that contain more details on each object were stored in an RDBMS which is more amenable to open system development.

\subsubsection{ArcFM Case Study}

Greenville Utilities was chartered by the North Carolina Assembly in 1905. It is organized as an independent agency of the City of Greenville and operates electric, water, sewer, and gas utilities for the City of Greenville and a portion of 
Pitt County. Greenville Utilities water operations serve 25,000 customers with 475 miles $(764 \mathrm{~km})$ of main, and sewer operations serve 20,000 customers with 333 miles $(535 \mathrm{~km}$ ) of main. Greenville Utilities uses ArcFM, SDE for their SQL server, and Arc/INFO software for implementing a GIS project for its electric, water, sewer, and gas services. ArcFM Viewer may be used by casual users, customer service representatives, field crews, and others to easily query, plot, and analyze spatial and related attribute data. This system is intended to improve business practice and customer service and will be used by all the utility services (ESRI, 1999).

\subsubsection{Pipeworks Case Study}

The City of Houston Department of Public Works and Engineering is implementing a \$3.6 million, two year project to design, develop, and support a turnkey Infrastructure Management System for water distribution, sanitary sewer, and storm sewer facilities management. The system is being built on the premise that customer calls, inventory data, current work activities, and historical information can be best integrated geographically, providing the best possible tool for improved customer service. This new system will feature ESRI's SDE technology with Oracle Enterprise Server as the DBMS. The main database server will be a clustered pair of DEC AlphaServer 4100 computers serving about 150 client connections. The system will use Pipeworks, ArcView, and ESRI's MapObjectsbased software suite to support call taking, service request investigation, work order generation, dispatching, and physical inspection activities. The project will also incorporate mobile computing to provide improved use of information and efficiency of operations throughout the department (ESRI,1999).

\section{References}

ASCE. 1998. New Poll Shows Voters Worried about Aging Infrastructure, ASCE News, ASCE, November 1998, pp.1-3.

AWWA. 1999. Welcome to the Information Age, Journal AWWA, AWWA, February 1999, 37pp.

Azteca Systems. 1999. White Paper: Pipeworks Data Model Concepts, Azteca Systems Home Page at http://www.azteca.com/data_model.htm.

Bryant, S.D., Young, T., Nicholson, J. 1999. Stormwater Infrastructure Inventory and GIS Database Meet Today's Needs, Tomorrow's Demands, Watershed \& Wet Weather technical Bulletin, WEF, Volume 4, Number 1, January 1999, pp.7-10.

Cannistra, J.R. 1999. Converting Utility Data for a GIS, Journal AWWA, AWWA, February 1999, pp.55-64.

ESRI. 1999. Utility Market Embraces ArcFM GIS Solution, Arc News, ESRI, Spring 1999, $4 \mathrm{pp}$. 
ESRI. 1999. City of Houston Launches Major GIS-Based Facilities Management Initiative, Arc News, ESRI, Spring 1999, 25pp.

Estes-Smargiassi, Stephen A. 1999. Massachusetts Water Resources Authority Uses GIS to Meet Objectives Cost-Effectively, Water Writes at http://www.esri.com/industries/water/writes/mwra.html, ESRI.

Doherty, M., Speer, E.D. 1999. Geographic Data Architecture Provides for Growth and Flexibility, Water Writes, ESRI, Spring 1999, pp.4-5.

Murillo, B., Tam, W., Boyd, G. 1996. City of Los Angeles Stormwater Information Management System. Proceedings, Watershed 96, Office of Water, EPA, Baltimore, Maryland, June 8, 1996. 
